\title{
Nutcracker syndrome with different clinical presentations in a young male population
}

\author{
Özgür ALBUZ ${ }^{1}$, Gökhan AKKURT ${ }^{1}$, Sezgin OKÇELIK ${ }^{2}$, Selami INCE ${ }^{3}$, Barış YAYLAK ${ }^{4}$
}

\footnotetext{
${ }^{1}$ Department of General Surgery, Keçiören Training and Research Hospital, Ankara, Türkiye.

${ }^{2}$ Department of Urology, Nevşehir State Hospital, Nevşehir, Türkiye.

${ }^{3}$ Department of Radiology, Beytepe Murat Erdi Eker State Hospital, Ankara, Türkiye

${ }^{4}$ Department of Cardiology, Doctor Siyami Ersek and Chest, Heart and Vascular Surgery Training and Research Hospital, İstanbul, Türkiye.
}

\section{SUMMARY}

The nutcracker syndrome (NCS) depends on mesoaortic compression of the left renal vein. It has different clinical entities. This study aimed to examine different clinical aspects of NCS.

This was a retrospective and descriptively designed study. The patients with abdominal pain, flank pain, or scrotal pain admitted to the Urology and General Surgery outpatient clinic between January 2014 and May 2016 were reviewed. All data were examined descriptively. Urologic and general surgical examinations were performed individually by a urologist and a general surgeon. The abdominal ultrasonography and computed tomography findings, blood pressure, white blood cell count, bilirubin tests, and urine tests were recorded.

Patients with inconsistent diagnostic data or missing outcomes were excluded. Five patients were diagnosed with NCS on scanning 134 patients. The mean age was 24 years (20-33 years). The first patient had left lower quadrant pain. The second patient also had left lower quadrant pain with microscopic hematuria and a mild increase in the total bilirubin level $(1.84 \mathrm{mg} / \mathrm{dL})$. The third patient presented left testicular pain and hypertension (160/100 $\mathrm{mm} \mathrm{Hg})$. Consequently, left side varicocele was found on physical examination and Doppler ultrasound. The fourth patient had leukocytosis (11,900), a mild increase in total bilirubin level $(1.73 \mathrm{mg} / \mathrm{dL})$, and left and right lower quadrant pain.

The radiological and laboratory entities must be taken into consideration with clinical findings for correct diagnosis because NCS may have different symptoms.

Key words: Nutcracker syndrome, mesoaortic compression, young people

\section{INTRODUCTION}

The nutcracker syndrome (NCS) is a clinically manifest variant of nutcracker phenomenon (NCP), renal vein entrapment syndrome, or mesoaortic compression of the left renal vein. It results most commonly from the compression of the left renal vein between the abdominal aorta (AA) and the superior mesenteric artery (SMA), although other variants may exist $(1,2)$. The disorder is easily missed by routine diagnostic methods. The exact incidence of the symptomatic NCS is not known (3). This clinical manifestation is a rare vascular abnormality. The term was first used by Grant (4) in the anatomical description 'the left renal vein as it lies between the aorta and the SMA resembles a nut between the jaws of a nutcracker' and later used to describe a pathological condition by De Schepper (5). NCS is caused by the compression of the left renal vein between the aorta and the SMA, where it courses in the fork formed at the bifurcation of these arteries (6). The syndrome has two forms. Anterior NCS is the compression of the left renal vein (LRV) between the aorta and the SMA, whereas posterior NCS is the compression between the vertebral column and the aorta (7).

The diagnosis of NCS is not well defined because of the broad clinical spectrum. These symptoms are associated with abdominal pain (classically left flank or pelvic pain), testicular pain in men or left lower quadrant pain in women, nausea, and vomiting (8-10). Additionally, it is associated with unilateral hematuria, gonadal vein syndrome, and varicocele $(11,12)$. Various degrees of proteinuria are present (13). This condition should not be confused with the SMA syndrome, which is 


\begin{tabular}{|c|c|c|c|c|c|c|c|c|c|}
\hline $\begin{array}{l}\text { Patient } \\
\text { no }\end{array}$ & $\begin{array}{l}\text { Age } \\
\text { (year) }\end{array}$ & Varicocele & $\begin{array}{l}\text { Microscopic } \\
\text { hematuria }\end{array}$ & $\begin{array}{c}\text { Total } \\
\text { bilirubin } \\
\text { level }\end{array}$ & Leukocytosis & $\begin{array}{c}\text { Systolic and } \\
\text { diastolic } \\
\text { pressures } \\
\text { (mm Hg) }\end{array}$ & Pain & Nausea & Other \\
\hline 1 & 20 & - & - & & & $120 \backslash 80$ & $\begin{array}{l}\text { Left lower } \\
\text { quadrant }\end{array}$ & & \\
\hline 2 & 22 & - & + & $1.84 \mathrm{mg} \backslash \mathrm{dL}$ & 9500 & $110 \backslash 70$ & $\begin{array}{l}\text { Left lower } \\
\text { quadrant }\end{array}$ & + & Left renal calculi \\
\hline 3 & 21 & + (Left side) & + & & & $160 \backslash 100$ & Left testicular & & \\
\hline 4 & 33 & & & $1.73 \mathrm{mg} \backslash \mathrm{dL}$ & 11,900 & $125 \backslash 85$ & $\begin{array}{l}\text { Left and right } \\
\text { lower quadrant }\end{array}$ & & \\
\hline 5 & 24 & & & & 8900 & $130 \backslash 85$ & $\begin{array}{l}\text { Abdominal } \\
\text { pain }\end{array}$ & & $\begin{array}{l}\text { Bloating } \\
\text { Constipation } \\
\text { Anorexia Weight } \\
\text { loss }\end{array}$ \\
\hline
\end{tabular}

the compression of the third portion of the duodenum by the SMA and the AA (1). This study focused on different clinical and laboratory entities of NCS. This retrospective review might reflect the experience in the diagnosis of NCS for a young male population with abdominal pain, flank pain, or scrotal pain during their admission to hospital.

\section{MATERIALS AND METHODS}

This was a retrospective and descriptively designed study. The patients with abdominal pain, flank pain, or scrotal pain admitted to Urology and General Surgery outpatient clinic were reviewed between January 2014 and May 2016. All data were examined descriptively. Urologic and general surgical examinations were performed individually by a urologist and a general surgeon. The abdominal ultrasonography and computed tomography (CT) findings, blood pressure, white blood cell count, bilirubin tests, and urine tests were recorded. Informed consent of each subject and approval of the local ethics committee were obtained.

\section{Demographic data}

Patients with inconsistent diagnosis data or missing outcomes were excluded. Five patients were diagnosed with NCS by scanning 134 patients (Table 1). Their mean age was 24 years (20-33 years).
The first patient had left lower quadrant pain. The second patient also had left lower quadrant pain with microscopic hematuria and a mild increase in the total bilirubin level $(1.84 \mathrm{mg} / \mathrm{dL})$. The third patient presented left testicular pain and hypertension (160/100 $\mathrm{mm} \mathrm{Hg}$ ). Consequently, left side varicocele was found on physical examination and Doppler ultrasound. The fourth patient had leukocytosis (11,900), a mild increase in total bilirubin level (1.73 $\mathrm{mg} / \mathrm{dL}$ ), and left and right lower quadrant pain. Despite no positive laboratory findings detected, the fifth patient presented with abdominal pain, bloating, constipation, anorexia, and weight loss.

The mean systolic and diastolic pressures of the patients with NCS were $129 \pm 18.84 \mathrm{~mm} \mathrm{Hg}$ and $84 \pm 10,83 \mathrm{~mm} \mathrm{Hg}$, respectively.

\section{RESULTS}

In the first patient, CT images showed the LRV compression between the aorta and SMA close to its origin, which resulted in proximal dilatation. No positive urinalysis was detected (Figure 1). In the second patient, CT detected a posterior NCS. It also revealed left renal calculi without any calyceal dilatation (Figure 2). In the third patient, Doppler ultrasound revealed grade III varicocele. Moreover, a posterior NCS was detected with oral and intravenous contrast-enhanced CT (Figure 3). In the fourth patient, total abdominal ultrasound was normal, but a posterior NCS was detected. The abdomen CT images showed the compression of the 


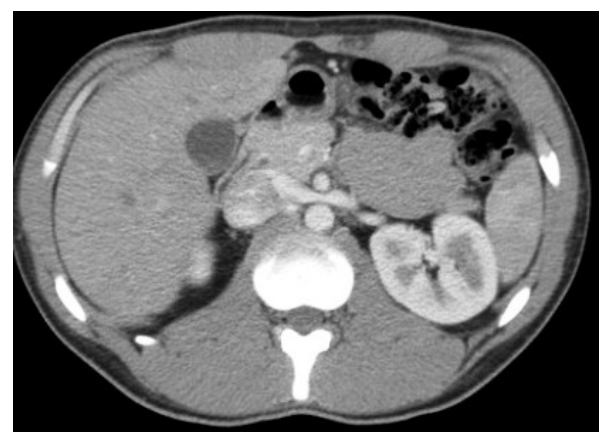

FIGURE 1: Axial contrast enhanced CT showing left renal vein entrapped between aorta and superior mesenteric artery.

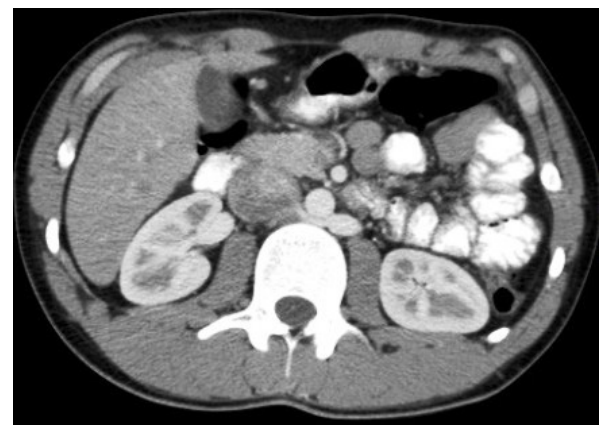

FIGURE 3: Axial contrast-enhanced CT examination indicates that the left renal vein is severely compressed by the abdominal aorta.

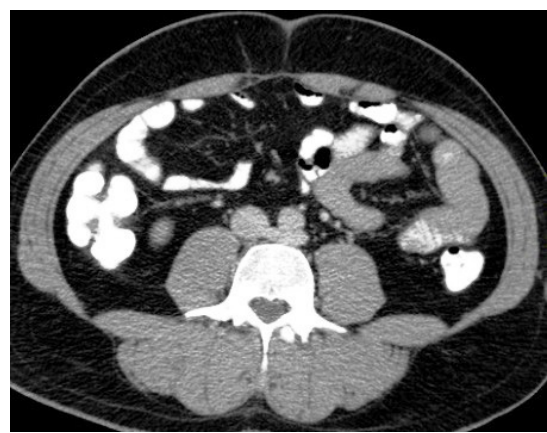

FIgURE 2: Axial CT view showing left renal vein compressed between the aorta and vertebral body

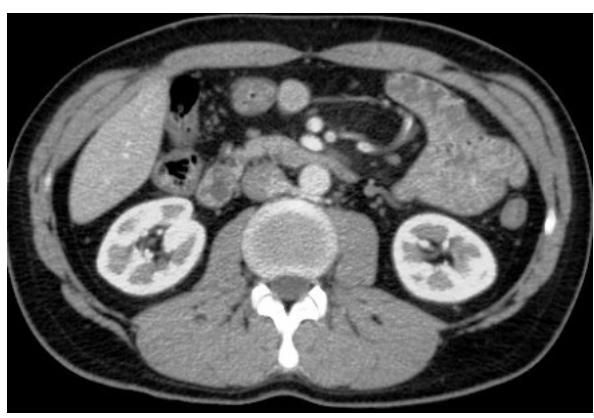

FIGURE 4: On axial CT view left retroaortic renal vein calibration markedly reduced by secondary to aorta compression

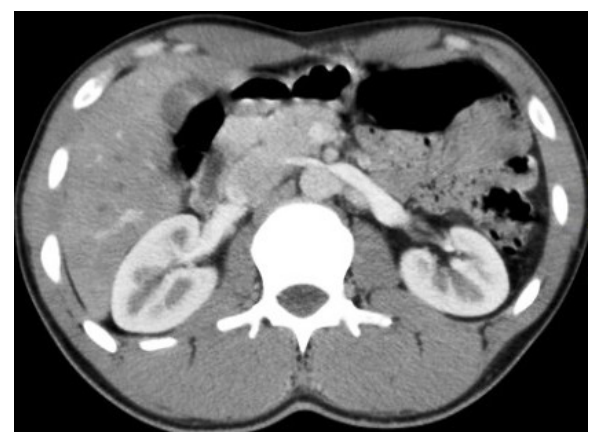

FIGURE 5: On the axial contrast-enhanced CT scan, the left renal vein is compressed significantly by the superior mesenteric artery

retroaortic LRV, which crossed between the aorta and the vertebral column (Figure 4). In the fifth patient, CT detected compression of LRV between the aorta and the SMA. The diagnosis of NCS was established based on these findings (Figure 5) (Table 2).

\section{DISCUSSION}

NCS frequently occurs in school children or young and healthy adults. It is extremely rare, but in reality it may be more common with easier diagnosis (14). The most common clinical manifestation of NCS is intermittent macroscopic hematuria (15). The symptoms of NCS are presumed to be the high pressure of the LRV, such as unilateral hematuria, gonadal vein syndrome, and varicocele. It is presumed that pain and hematuria are connected with the high pressure of the LRV and the ureteropelvic varix (16). The high pressure of the LRV congests intrarenal vessels to rupture the weak veins of the calyceal fornix and the collecting system. In rare cases, anemia, proteinuria, and varicose veins occur (17). The anterior nutcracker syndrome results from compression as the LRV passes between the 


\begin{tabular}{|clc}
\hline TABLE 2: Computed tomography findings of patients with nutcracker syndrome. \\
\hline $\begin{array}{c}\text { Patient } \\
\text { no }\end{array}$ & CT findings & Diagnosis \\
\hline 1 & Compression of LRV between the aorta and SMA & Anterior nutcracker syndrome \\
\hline 2 & $\begin{array}{l}\text { Compression of LRV (retroaortic) between the aorta and } \\
\text { the vertebral body }\end{array}$ & Posterior nutcracker syndrome and left renal calculi \\
& $\begin{array}{l}\text { Severe compression of LRV (retroaortic) by the abdominal } \\
\text { aorta }\end{array}$ & Posterior nutcracker syndrome \\
\hline 4 & $\begin{array}{l}\text { Compression of LRV (retroaortic) secondary to aortic } \\
\text { compression }\end{array}$ & Posterior nutcracker syndrome \\
5 & Significant compression of LRV by the SMA & Anterior nutcracker syndrome \\
\hline
\end{tabular}

SMA and the aorta and is, in general, followed by the subsequent development of venous varicosities of the renal pelvis, ureter, and the gonadal vein. This phenomenon is manifested as pain in the left flank and/or abdomen, unilateral hematuria, and, occasionally, a varicocele in males and abnormal menstruation in females $(18,19)$. Two patients in the present study had anterior NCS; one of them experienced left lower quadrant pain, and the other one abdominal pain. The term "posterior NCP" refers to the left renal venous hypertension secondary to the compression of the retroaortic LRV, which crosses between the aorta and the vertebral column (20).

The main presenting symptom is hematuria with or without left flank pain. Three patients in the present study had posterior nutcracker syndrome, and two of them had left flank pain. Further, among these three patients, only two had microscopic hematuria and one had left renal calculi.

This disorder is easily overlooked if routine diagnostic procedures are used alone, and consequently, its incidence is likely to be underestimated. Compression of the LRV was first described in 1950 (21). In 1972, De Schepper described compression of the LRV between the aorta and the SMA as NCS (5). Unilateral hematuria is due to abnormal communication between the submucosal venous plexus and the calyceal system presumably induced by renal venous hypertension (11). The gonadal vein syndrome is characterized by abdominal and flank pain exacerbated by sitting, standing, or walking (22). Zerhouni et al. reported NCP in three patients investigated for varicocele (12). Only one patient in the present study had a varicocele. The pathophysiology of the nutcracker syndrome is not well known. It was proposed that posterior renal ptosis with stretching of the LRV might be a causal factor (14). Recent studies identified abnormal branching of the SMA from the aorta as its cause $(18,19)$. NCS cannot be diagnosed using routine diagnostic methods. Therefore, it is easily misdiagnosed or undiagnosed. The terms NCP and NCS are sometimes used interchangeably in the literature. Shin and Lee accentuated that the nutcracker anatomy was not always accompanied by clinical symptoms and some of the anatomic findings suggestive of nutcracker might stand for a normal variant or be accounted for by other conditions (23). Imaging, such as ultrasonography (US), Doppler US, CT, or magnetic resonance imaging, is required to diagnose NCS. Acute narrowing of the LRV at the level of SMA (beak sign), lateral (hilar) dilatation, and the presence of collateral pathways detected on CT imaging can be help in the diagnosis of NCS. However, the diagnostic procedure (considering the reference standard for establishing the diagnosis of N(S) is invasive selective left renal phlebography with the measurement of the pressure gradient between the LRV and IVC $(24,25)$. The present study indicated that CT is helpful in terms of diagnosis. Furthermore, SMA syndrome is a rare cause of abdominal pain, nausea, and vomiting, which may be undiagnosed in patients presenting to the emergency department. SMA syndrome is arteriomesenteric obstruction of the duodenum, which is characterized by compression of the third portion of the duodenum by SMA (as it passes over this portion of the duodenum). NCS is characterized by impeded 
outflow from LRV into the inferior vena cava due to extrinsic LRV compression. In addition to an appropriate clinical history, CT findings indicating decreased aortomesenteric angle and a shortened aortomesenteric distance may suggest the diagnosis of both the SMA syndrome and the accompanying NCS (26).

\section{CONCLUSIONS}

The most important step is clinical suspicion for diagnosis because NCS may present with different symptoms. Although noninvasive imaging techniques may prove highly valuable in the diagnostic management of patients with hematuria or flank pain due to NCS, the findings are not always specific to this disease. Hence, it is recommended to coordinate with all other related clinics and give priority to CT findings and radiological and laboratory entities for correct diagnosis.

\section{REFERENCES}

1. Kurklinsky AK, Rooke TW. Nutcracker phenomenon and nutcracker syndrome. Mayo Clin Proc 2010;85 (6):552-559. doi:10.4065/ mcp.2009.0586.

2. Sugimoto I, Takashi O, Ishibashi H, Takeuchi N, Nagata $Y$, Honda Y. Left Renal Vein Entrapment Syndrome (Nutcracker Syndrome) treated with Left Renal Vein Transposition Jnp J Vasc Surg 2001; 10: 503-7.

3. Ahmed K, Sampath R, Khan MS. Current trends in the diagnosis and management of renal nutcracker syndrome: a review. Eur J Vasc Endovasc Surg 2006;31 (4):410-416. doi:10.1016/j.ejvs.2005.05.045.

4. Grant JCB. Methods of Anatomy. Baltimore, MD: Williams and Wilkins, 1937; 158.

5. De Schepper A. ("Nutcracker" phenomenon of the renal vein and venous pathology of the left kidney). J Belge Radiol 1972;55 (5):507-511.

6. Chen YM, Wang IK, Ng KK, Huang CC. Nutcracker syndrome: an overlooked cause of hematuria. Chang Gung Med J 2002;25 (10):700-705.

7. Özkan MB, Bilgici MC, Hayalioglu E. Anterior and posterior nutcracker syndrome accompanying left circumaortic renal vein in an adolescent. Case report. Arch Argent Pediatr 2016;114(2):114116.

8. Oteki T, Nagase $S$, Hirayama A, Sugimoto $H$, Hirayama K, Hattori $\mathrm{K}$, Koyama A. Nutcracker syndrome associated with severe anemia and mild proteinuria. Clin Nephrol 2004;62 (1):62-65.

9. Barnes RW, Fleisher HL, 3rd, Redman JF, Smith JW, Harshfield DL, Ferris EJ. Mesoaortic compression of the left renal vein (the socalled nutcracker syndrome): repair by a new stenting procedure. J Vasc Surg 8 1998;(4):415-421.
10. Hilgard $\mathrm{P}$, Oberholzer $\mathrm{K}$, Meyer zum Buschenfelde $\mathrm{KH}$, Hohenfellner R, Gerken G. (The "nutcracker syndrome" of the renal vein (superior mesenteric artery syndrome) as the cause of gastrointestinal complaints). Dtsch Med Wochenschr 1998;123 (31-32):936-940. doi:10.1055/s-2007-1024101.

11. Lopatkin AN, Morozov AV, Lopatkin LN. Essential renal hemorrage. Eur Urol 1978;4:115-118.

12. Zerhouni EA, Siegelman SS, Walsh PC, White RI. Elevated pressure in the left renal vein in patients with varicocele: preliminary observation. J Urol 1980;123:512-513.

13. Kim SH, Cho SW, Kim HD, Chung JW, Park JH, Han MC. Nutcracker syndrome: diagnosis with Doppler US. Radiology 1996;198 (1):9397. doi:10.1148/radiology.198.1.8539413.

14. Wendel RG, Crawford ED, Hehman KN. The "nutcracker" phenomenon: an unusual cause for renal varicosities with hematuria. J Urol 1980;123 (5):761-763.

15. Takebayashi S, Ueki T, Ikeda N, Fujikawa A. Diagnosis of the nutcracker syndrome with color Doppler sonography: correlation with flow patterns on retrograde left renal venography. AJR Am J Roentgenol 1990;172 (1):39-43. doi:10.2214/ajr.172.1.9888735.

16. Choi SH, Kim JS, Shin TS, Lee YS, Kim HJ, Choi NG. Nutcracker Syndrome Diagnosed with 3-Dimensional Computed Tomography Angiography. Korean Journal of Urology 2009;50(7): 711-713.

17. Little $A F$, Lavoipierre AM. Unusual clinical manifestations of the Nutcracker Syndrome. Australas Radiol 2002;46 (2):197-200.

18. Hohenfellner $M$, Steinbach $F$, Schultz-Lampel $D$, Schantzen $W$, Walter K, Cramer BM, Thuroff JW, Hohenfellner R. The nutcracker syndrome: new aspects of pathophysiology, diagnosis and treatment. J Urol 1991;146 (3):685-688.

19. Shokeir AA, el-Diasty TA, Ghoneim MA. The nutcracker syndrome: new methods of diagnosis and treatment. Br J Urol 1994;74 (2):139-143.

20. Lau JL, Lo R, Chan FL, Wong KK. The posterior "nutcracker": hematuria secondary to retroaortic left renal vein. Urology 1986;28 (5):437-439.

21. El Sadr AR, Mina A. Anatomical and surgical aspects in the operative management of varicoceles. Urol Cut Rev 1950;54:257262

22. Coolsaet BLRA. Ureteric pathology in relation to right and left gonadal veins. Urology 1978;12: 40-9.

23. Shin JI, Lee JS. Nutcracker phenomenon or nutcracker syndrome? Nephrol Dial Transplant 2005;20 (9):2015. doi:10.1093/ndt/gfi078.

24. Barsoum MK, Shepherd RF, Welch TJ. Patient with both Wilkie syndrome and nutcracker syndrome. Vasc Med 2008;13(3):247250. doi:10.1177/1358863X08092272.

25. Waseem M, Upadhyay R, Prosper G. The nutcracker syndrome: an underrecognized cause of hematuria. Eur J Pediatr 2012;171 (8):1269-1271. doi:10.1007/s00431-012-1761-1.

26. Inal $M$, Daphan BU, Bilgili MYK. Superior Mesenteric Artery Syndrome Accompanying With Nutcracker Syndrome: A Case Report., Iran Red Crescent Med J 2014;16(10) 14755. 